\title{
KINERJA ROLE ONLINE SYSTEM TICKETING RAHARJA (ROOSTER) DALAM MENUNJANG SISTEM PELAYANAN IDUHELP! PADA PERGURUAN TINGGI
}

\author{
Untung Rahardja ${ }^{1}$ \\ Meta Amalya Dewi \\ Citra Destianty ${ }^{3}$ \\ e-mail: untung@raharja.info,meta@raharja.info, citradestianty@raharja.info
}

Diterima : 08 Nopember 2013 / Disetujui : 26 Nopember 2013

\begin{abstract}
The advancement of information technology has positive impacts on life, especially in the service system. Current university has implemented a system information, applicable campuswide known as iDuHelp service system. However, problems are identified in the iDuHelp service system, which will be further described in detail. The problem is then resolved with the support of the performance from ROOSTER (Role Online System Ticketing Raharja), by providing unique ticket numbers which will be transferred to the relevant parties in order to provide accurate information. Many related methods of this study, including the methods of iLearning, also the road map of the study and mindmapping, are further described in detail and will eventually produce clearer research outcomes. The method of analysis is also done through three stages, namely the identification of information needed, identification of system requirements, and eventually the survey on the current system. Described in this article are the problems that arise and the solution to the problem under study. There is also a flowchart workflow. In the prototype implementation of iDuHelp, will be shown the system performance of ROOSTER and the listing program. It can be concluded that the performance of ROOSTER can maximize the service system iDuHelp on higher education platform .
\end{abstract}

Keywords: system services, ROOSTER, iDuHelp!.

1. Dosen Jurusan Sistem Informasi, STMIK Raharja

Jl. Jend Sudirman No. 40 Modern Cikokol-Tangerang Telp. 5529692

2. Dosen Jurusan Sistem Informasi, STMIK Raharja

Jl. Jend Sudirman No. 40 Modern Cikokol-Tangerang Telp. 5529692

3. Mahasiswa Jurusan Sistem Informasi, STMIK Raharja

Jl. Jend Sudirman No. 40 Modern Cikokol-Tangerang Telp. 5529692 


\begin{abstract}
ABSTRAKSI
Perkembangan teknologi informasi merupakan dampak positif bagi kehidupan, terutama dalam sistem pelayanan. Saat ini Perguruan Tinggi Raharja telah menerapkan sistem pelayanan kampus yang dikenal dengan sistem pelayanan iDuHelp!.Diidentifikasikan terdapat permasalahan pada sistem pelayanan iDuHelp. Namun, masalah tersebut terselesaikan dengan adanya penunjang dari kinerja ROOSTER (Role Online System Ticketing Raharja) yaitu dengan memberikan sebuah nomor tiket yang akan dialihkan kepada pihak terkait agar dapat memberikan informasi yang akurat. Banyak metode terkait dari penelitian ini, diantaranya dengan metode iLearning, sehingga road map penelitian pun dapat dijabarkan secara detail dan akan menghasilkan luaran penelitian yang jelas dengan mindmapping. Selain itu metode analisis juga dilakukan melalui tiga tahapan yaitu identifikasi kebutuhan informasi, identifikasi persyaratan sistem, dan survey atas sistem yang sedang berjalan. Dalam artikel ini dijelaskan mengenai masalahmasalah yang timbul serta pemecahan masalah yang diteliti dengan menggunakan alur flowchart. Pada implementasinya ditampilkan prototype iDuHelp! serta sistem kinerja ROOSTER dan listing program yang ditulis. Maka dapat disimpulkan bahwa kinerja ROOSTER dapat memaksimalkan sistem pelayanan iDuHelp! pada Perguruan Tinggi Raharja.
\end{abstract}

Kata Kunci : Sistem Pelayanan, ROOSTER, iDuHelp!.

\title{
PENDAHULUAN
}

Konsep pelayanan informasi yang semakin berkembang dan banyak diadopsi belakangan ini adalah berbasis pada pendekatan media website dan sedikit demi sedikit mulai meninggalkan format yang sebelumnya dilakukan secara fisik (person to person direct contact). Seiring dengan perkembangan Teknologi Informasi (TI) yang semakin pesat, kebutuhan akan pelayanan berbasis TI menjadi tidak dapat dihindarkan lagi. Hal ini disebabkan adanya pengaruh perkembangan teknologi terhadap aspek kehidupan, contohnya adalah bagaimana manusia melakukan komunikasi dengan sesamanya. Pengaruh perkembangan teknologi tersebut memberikan dampak yang positif terhadap suatu sistem pelayanan informasi. Dampak tersebut memberikan kemudahan dalam mengakses informasi, sehingga penggunaan dalam sebuah pelayanan menjadi lebih efektif dan cepat .

Pelayanaan Informasi yang dapat diakses dengan mudah, merupakan harapan bagi setiap manusia untuk dapat memperoleh informasi. Perkembangan teknologi dalam dunia informatika dari waktu ke waktu pun mengalami kemajuan yang sangat pesat sehingga membuat semua institusi pendidikan ingin mengembangkan dan menggunakan kecanggihan teknologi untuk dapat meningkatkan kinerjanya. Saat ini 
pemenuhan atas suatu kebutuhan informasi tidak bisa lepas dari pemanfaatan media komputer yang diakses dengan jaringan internet. Dengan adanya jaringan internet maka seseorang akan lebih mudah dalam memperoleh informasi tanpa memakan banyak waktu dan juga tidak mengenal adanya batasan jarak.

Penyampaian informasi yang dilakukan selama ini oleh Perguruan Tinggi Raharja dengan menggunakan 2 metode yaitu metode tradisional dan menggunakan metode teknologi jaringan komputer. Metode tradisional disini umumnya juga dilakukan oleh penyelenggara pendidikan (kampus) lainnya yaitu dengan menggunakan media majalah dinding (mading), spanduk dan poster. Sedangkan untuk metode kedua yang dilakukan adalah dengan menyampaikan informasi yang berhubungan dengan kegiatan kampus melalui media elektronik khususnya media website (online) dan juga jejaring sosial (social networking). Salah satu contoh yang paling sederhana adalah mahasiswa yang sebelumnya dalam mendapatkan informasi memerlukan banyak waktu dan tenaga, karena saat itu masih menggunakan cara berinteraksi secara fisik, seperti ingin bertanya mengenai perihal seputar akademik kampus, mahasiswa harus mencari pihak yang berkaitan agar mahasiswa tersebut mendapatkan informasi. Pihak kampus menyadari bahwa metode kedua memiliki banyak kelebihan dalam hal penyampaian informasi yang lebih cepat dan juga tepat sasaran. Tapi kini dengan memanfaatkan media komputer yang diakses dengan jaringan internet, Perguruan Tinggi Raharja telah mengembangkan sebuah sistem pelayanan online yaitu sistem pelayanan iDuHelp!.

Sistem pelayanan iDuHelp! ini merupakan Sistem penerapan campus service system pelayanan secara in site dan off site dalam mendukung kegiatan iLearning Education (iDU) pada Perguruan Tinggi Raharja[1]. Pelayanan iDuHelp! yang dilakukan secara in site artinya pelayanan yang dilakukan melalui live chat dengan operator. Sedangkan pelayanan iDuHelp! secara off site artinya pelayanan yang dilakukan dengan mengirimkan isi pesan kemudian terdapat proses tunggu untuk memperoleh informasi. Di dalam pelayanan iDuHelp! terdapat beberapa operator yang siap sedia melayani para mahasiswa untuk mendapatkan informasi. Namun permasalahan yang sering terjadi pada sistem pelayanan iDuHelp! adalah ketika pertanyaan dari mahasiswa tidak dapat dijawab oleh operator, karena operator iDuHelp! tidak dapat memprediksi atau mengetahui pertanyaan-pertanyaan yang dibutuhkan oleh para mahasiswa, sehingga operator iDuHelp! harus mencari tambahan informasi dari pihak yang terkait secara langsung agar dapat menjawab pertanyaan dari para mahasiswa. Hal ini menyebabkan operator iDuHelp! membutuhkan waktu yang cukup lama untuk mendapatkan sebuah informasi yang diperlukan. Oleh karena itu, pelayanan iDuHelp! membutuhkan sebuah sistem tambahan yang dapat menunjang proses layanannya. Untuk menjawab permasalahan 
yang ada tersebut, maka dibutuhkan sistem ROOSTER (Role Online System Ticketing Raharja) yang merupakan sistem pelayanan informasi dengan menggunakan sebuah tiket yang akan diberikan kepada pihak yang terkait, agar dapat memberikan informasi yang akurat, sehingga dengan adanya sistem ROOSTER dapat membantu pelayanan iDuHelp! menjadi lebih optimal dalam pencapaian sebuah informasi.

Kinerja ROOSTER dalam menunjang sistem pelayanan iDuHelp! pada Perguruan Tinggi Raharja diharapkan dapat memberikan informasi yang terpercaya, sehingga mahasiswa tidak lagi meragukan informasi yang didapatkan dari sistem pelayanan iDuHelp! dan diharapkan mahasiswa tidak lagi mengalami kesulitan dalam mengakses informasi seputar akademik perkuliahan tanpa harus membuang banyak waktu.

\section{PERMASALAHAN}

Sistem pelayanan merupakan pokok utama yang harus diperhatikan, karena dengan adanya sistem pelayanan maka akan dapat memenuhi kebutuhan informasi seseorang. Sehingga mutu dan kualitas dari suatu pelayanan sangat penting dalam meningkatkan sumber daya sistem yang telah diterapkan. Pada dasarnya Perguruan Tinggi Raharja telahmemiliki pelayanan iDuHelp!. Namun pelayanan iDuHelp! masih belum optimal.

Dalam pelayanan iDuHelp! terdapat 4 (empat) permasalahan yang telah diuraikan yaitu permasalahan pertama adalah ruang lingkup yang terlalu luas menyebabkan operator iDuHelp! tidak dapat memprediksi informasi yang dibutuhkan. Permasalahan yang kedua yaitu tidak adanya pihak yang terkait dalam sistem, sehingga informasi yang didapatkan membutuhkan banyak waktu untuk mencari pihak yang terkait.

Permasalahan yang ketiga adalah operator iDuHelp! yang masih kurang menguasai teknik dari sistem pelayanan iDuHelp!, sehingga pelayanan terlihat tidak optimal. Serta permasalahan yang keempat adalah prosedur dalam pemberian informasi belum terarah dengan jelas, hal ini dapat menyebabkan pelayanan iDuHelp! ternilai kurang memuaskan.

Dari keempat permasalahan diatas dapat disimpulkan secara detail penjabaran pelayanan iDuHelp! dengan menggunakan aplikasi Mind Mapping. Dikarenakan proses pembuatan aplikasi ini tidak mudah, dan banyak membutuhkan proses yang bertahap, sehingga dilakukan proses pembuatan aplikasi yang sebenarnya. 


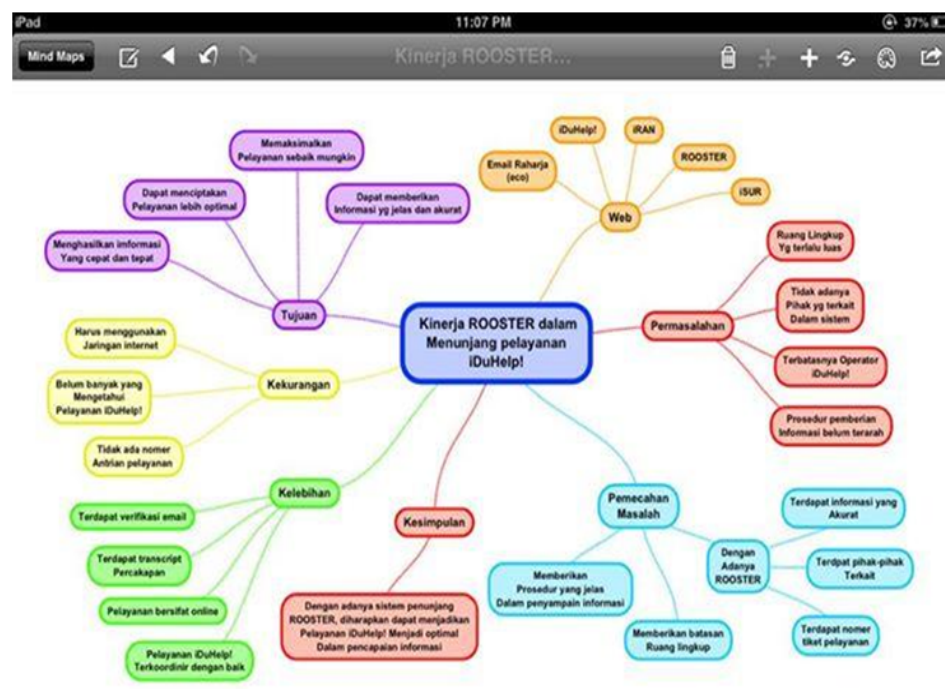

Gambar 1. Mind Mapping Penjabaran pelayanan iDuHelp!

Pelayanan iDuhelp! yang sedang berjalan masih memerlukan perbaikan dalam segi pelayanan, sehingga diperlukan perbaikan kualitas dan perkembangan terhadap pelayanan iDuHelp! agar terlihat stabil dalam proses pencapaian informasi. Terdapat grafik pemcapaian informasi dengan menggunakan layanan iDuHelp! sebagai berikut

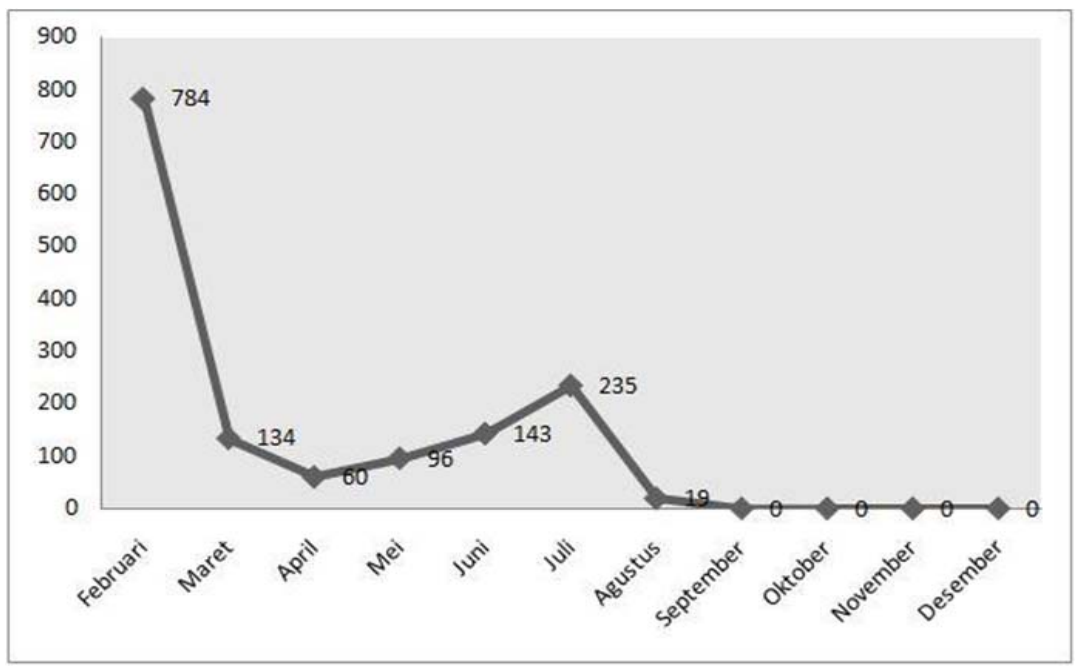

Gambar 2. Grafik Pelayanan iDuHelp! 
Tampak pada gambar diatas, merupakan tampilan grafik perkembangan mahasiswa terhadap layanan iDuHelp! pada Perguruan Tinggi Raharja yang tidak stabil pada setiap bulannya bahkan cenderung menurun dikarenakan tingkat kebutuhan dalam pelayanan tidak dapat diprediksi. Sedangkan permasalahan yang paling umum terjadi adalah saat operator tidak bisa memberikan informasi dikarenakan ruang lingkup yang terlalu luas dan tidak ada media jawaban, sehingga informasi yang didapatkan oleh mahasiswa kurang akurat, hal ini akan berdampak buruk terhadap pelayanan iDuHelp!.

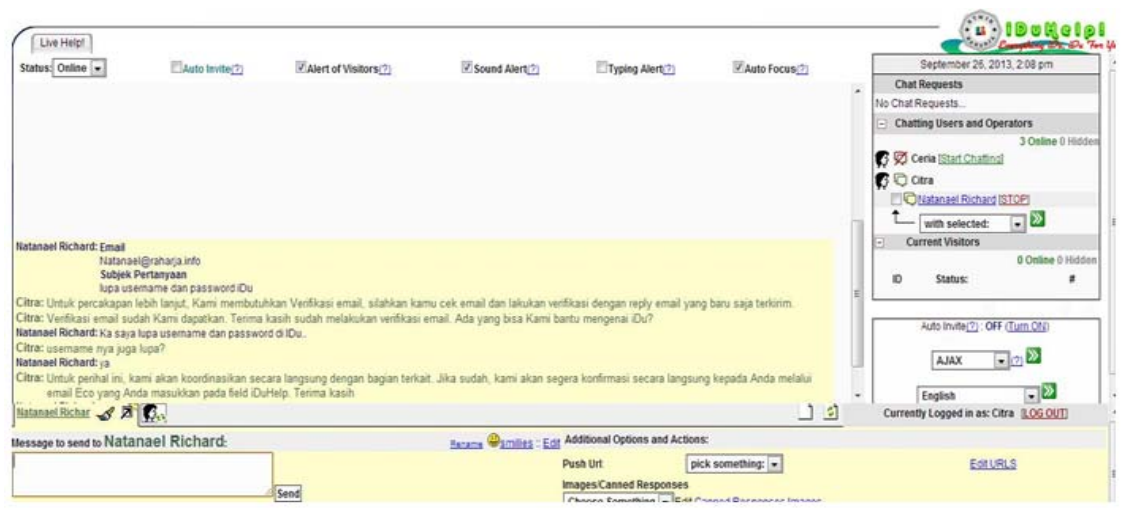

Gambar 3. Live Chat iDuHelp Online

Pada gambar diatas, merupakan tampilan live chat online yang dilakukan operator iDuHelp! terhadap mahasiswa yang membutuhkan informasi, namun terlihat chat tersebut terhenti dikarenakan operator tidak bisa memberikan informasi yang sesuai dengan keinginan mahasiswa tersebut. Keterbatasan operator iDuHelp! dalam menjawab pertanyaan yang tidak mampu memberikan informasi yang jelas kepada mahasiswa sehingga terjadinya keterlambatan proses penyampaian informasi, dalam hal ini kinerja ROOSTER (Role Online System Ticketing Raharja) sangat berperan penting untuk dapat mengurangi permasalahan-permasalahan yang ada pada sistem pelayanan iDuHelp!.

\section{LITERATURE REVIEW}

Dalam upaya untuk meningkatkan mutu pelayanan berbasis online perlu dilakukan studi pustaka sebagai salah satu dari penerapan metode penelitian yang akan dilakukan. Diantaranya adalah mengidentifikasikan kesenjangan (identify 
gaps), menghindari pembuatan ulang (reinventing the wheel), mengidentifikasikan metode yang pernah dilakukan, serta mengetahui orang lain yang spesialisasi dan area penelitian yang sama dibidang ini. Beberapa literature review tersebut adalah sebagai berikut:

1. Penelitian yang dilakukan oleh Ery Hartati dari STMIK MDP Palembang, Indonesia pada tahun 2008 yang berjudul " Sistem Pemesanan Dan Pembelian Tiket Bioskop Secara Online Dengan menggunakan Active Server Pages.Net Berbasis Web Dan Wireless Application Protocol”. Pada penelitian ini menjelaskan mengenai sistem pemesanan dan pembelian tiket bioskop. Interaksi pelanggan yang dulunya dilakukan secara fisik (person to person direct contact) mulai bergeser ke elektronik (communication through technology innovations) karena komunikasi secara elektronik relatif dapat dilakukan secara efisien, efektif, akurat, aman, nyaman, dan berkualitas. Sejak dulu hingga saat ini, penonton yang ingin membeli tiket bioskop harus mengantri di loket penjualan tiket untuk membeli tiket bioskop. Cara ini relatif tidak efektif karena penonton harus mengantri dalam antrian yang cukup panjang dan cukup lama. Solusi untuk membuat sistem baru yaitu dengan menggunakan sistem pemesanan tiket bioskop secara online dengan menggunakan Active Server Pages.net berbasis web dan Wireless Application Protocol (WAP). Pada sistem yang baru, penonton dapat melihat film yang akan ditayangkan di bioskop, mendapatkan informasi harga tiket pada bioskop yang berbeda lokasinya, mendapatkan informasi ketersediaan tiket dan lokasi tempat duduk, dan membeli tiket bioskop melalui web atau melalui handheld mobile device yang mendukung penggunaan WAP sehingga penonton tidak perlu lagi mengantri dan menghabiskan waktu untuk mengantri tiket bioskop. Dalam penelitian ini korelasi dengan penelitian yang dilakukan sangat berkaitan, karena telah menjelaskan mengenai sistem pelayanan yang dulunya masih berinteraksi secara fisik namun saat ini telah menggunakan sistem baru secara online[2].

2. Penelitian yang dilakukan oleh Lili Luo dari University of North Carolina at Chapel Hill, Chapel Hill, North Carolina, USA, pada tahun 2007 yang berjudul "Chat Reference Competencies: Identification From a Literature Review And Librarian Interviews".Penelitian ini bertujuan untuk menyajikan identifikasi kompetensi chatting, dengan tujuan menyediakan tujuan perilaku untuk kinerja chatting profesional. Upaya identifikasi kompetensi disajikan dalam penelitian ini terdiri dari dua bagian: sebuah tinjauan menyeluruh literatur referensi chatting dan wawancara dengan sampel kemudahan referensi pustakawan chatting berpengalaman untuk memperoleh persepsi mereka tentang pentingnya referensi kompetensi chat. Temuan yang dihasilkan adalah 
tiga jenis referensi kompetensi chatting diidentifikasi: kompetensi inti untuk referensi umum, kompetensi untuk referensi umum tetapi disorot dalam lingkungan chatting, dan kompetensi spesifik untuk chatting layanan referensi. Kompetensi yang diidentifikasi dapat berfungsi sebagai dasar yang kuat untuk desain program pelatihan dan pendidikan untuk referensi pustakawan chat. Nilai yang diharapkan pada penelitian ini adalah dapat menghasilkan daftar yang diperlukan untuk referensi obrolan yang bisa menguntungkan pelatihan dan pendidikan pustakawan referensi chatting. Dalam penelitian ini korelasi dengan penelitian yang dilakukan adalah penggunaan chat yang profesional agar dapat memberikan kepuasan[3].

3. Penelitian ini dilakukan oleh John R.Olson dari University of St Thomas, Minneapolis, Minnesota, USA, pada tahun 2005 yang berjudul "Internet Ticketing In A Not-For-Profit, Service Organization: Building Customer Loyalty”. Penelitian ini membahas tentang melihat cara dimana banyak organisasi sekarang melakukan bisnis. Internet telah membuat pemindahan informasi mudah tapi memenuhi pesanan online telah terbukti menjadi tantangan. Hasil penelitian menunjukkan bahwa pelanggan menyadari manfaat yang signifikan dari menggunakan internet untuk membeli tiket konser. Pelanggan juga menunjukkan bahwa mereka puas dengan pengalaman layanan internet mereka. Peran internet dalam organisasi akan berubah secara dramatis selama dekade berikutnya. Untuk organisasi yang mencoba untuk menggunakan internet sebagai media penjualan utama, mereka harus menyadari bahwa kesuksesan mereka bergantung pada pengembangan basis pelanggan yang berkelanjutan. Untuk organisasi yang didirikan, integrasi internet ke dalam bisnis yang ada akan menjadi salah satu kunci keberhasilan dimasa depan. Dalam penelitian ini korelasi dengan penelitian yang dilakukan adalah bahwa peranan internet dapat memberikan kepuasan terhadap pelayanan serta telah memberikan manfaat yang besar guna mewujudkan pelayanan yang optimal[4].

4. Penelitian yang dilakukan oleh Untung Rahardja, Fery Sudarto dan Linda Octavia dari Perguruan Tinggi Raharja, Indonesia pada tahun 2013 yang berjudul ”iDuHelp!: Penerapan Campus Service System iDuHelp! Dalam Mendukung Kegiatan iLearning Education (IDU) Pada Perguruan Tinggi”. Penelitian ini menjelaskan pelayanan informasi secara online dan offline. Dengan adanya sistem penerapan campus service system iDuHelp! dalam mendukung kegiatan iLearning Education pada perguruan tinggi ini diharapkan nantinya bagi calon mahasiswa tidak kesulitan dalam mengakses informasi mengenai hal-hal yang berhubungan dengan penerimaan mahasiswa baru dan diharapkan juga dengan adanya sistem ini, para calon mahasiswa 
tidak kesulitan untuk mendaftar dimanapun dan kapanpun, selain itu bisa mengetahui perihal fasilitas dan news apa saja yang dimiliki dari kampus tersebut tanpa harus mengunjungi atau datang langsung ke kampus tersebut. Dalam penelitian ini korelasi yang berhubungan dengan penelitian yang di lakukan adalah pelayanan informasi yang digunakan secara online dan offline[5].

5. Penelitian yang dilakukan oleh Untung Rahardja, Nur Azizah dan Santika Dewi dari Perguruan Tinggi Raharja, Indonesia pada tahun 2013 yang berjudul"Sistem Pelayanan Dukungan Role Online System Ticketing Raharja (ROOSTER) Dengan Menggunakan E-Ticket”. Penelitian ini menjelaskan sebuah website sebagai media interaksi dengan menggunakan $e$ Ticket yang bertujuan untuk memudahkan proses pelayanan dukungan, selain itu juga memberikan kemudahan kepada pemakai untuk dilayani. Proses pelayanan dukungan dapat dilakukan dengan cara online sehingga menambah kemudahan dalam proses pelayanan dukungan. Pada Perguruan Tinggi Raharja, sistem pelayanan dukungan ROOSTER (Role Online System Ticketing Raharja) yang diterapkan ditujukan untuk memberikan pelayanan yang efektif dan efesien kepada seluruh civitas akademika Perguruan Tinggi Raharja. Dalam penelitian ini korelasi yang berhubungan dengan penelitian yang dilakukan adalah penggunaan ticketing online yang dapat memudahkan sitem pelayanan menjadi terarah dan tersusun secara sistematis dengan adanya penomoran tiket yang terurut[6].

Dari kelima Literature Review yang ada, banyak korelasi yang saling berkaitan satu sama lain, salah satunya dengan adanya media website yang terhubung dengan jaringan internet. Hal ini dikarenakan internet telah mampu memberikan manfaat yang dapat memudahkan seseorang untuk mendapatkan informasi. Selain itu telah banyak penelitian mengenai Chat reference competencies: identification from a literature review and librarian interviews, Internet Ticketing In A NotFor-Profit, Service Organization: Building Customer Loyalty, Sistem Pemesanan Dan Pembelian Tiket Bioskop Secara Online Dengan menggunakan Active Server Pages.Net Berbasis Web Dan Wireless Application Protocol, iDuHelp!: Penerapan Campus Service System iDuHelp! Dalam Mendukung Kegiatan iLearning Education (IDU) Pada Perguruan Tinggi, Sistem Pelayanan Dukungan Role Online System Ticketing Raharja (ROOSTER) Dengan Menggunakan E-Ticket. Namun dapat disimpulkan pula bahwa belum ada peneliti yang secara khusus membahas mengenai Kinerja Role Online System Ticketing Raharja dalam menunjang sistem pelayanan iDuHelp! pada Perguruan Tinggi 


\section{PEMECAHAN MASALAH}

Untuk mengatasi berbagai masalah yang ada, maka diperlukan proses yang cepat dan efesien dalam memberikan pelayanan yang baik dalam sebuah institusi pendidikan, terlebih untuk mewujudkan suatu sistem informasi yang akurat. Untuk itu permasalahan yang ada harus dipecahkan yaitu dengan adanya sistem pelayanan ROOSTER melalui ticketing online.

ROOSTER merupakan sistem pelayanan informasi dengan menggunakan sebuah tiket yang akan diberikan kepada pihak yang terkait agar dapat memberikan informasi yang akurat. Dengan adanya tiket maka pelayanan akan menjadi lebih terarah. ROOSTER dapat diakses dimanapun dan kapanpun dengan menggunakan jaringan internet, sehingga kinerja ROOSTER dapat dijadikan inovasi baru dalam menunjang sistem pelayanan iDuHelp![7].

Oleh karena itu berdasarkan analisa dari segi kekurangan serta kebutuhan saat ini, kebutuhan terhadap sistem hendaknya dapat melihat dan menambahkan data-data serta informasi yang dibutuhkan, demi mengoptimalkan kinerja dari sistem pelayanan yang ada pada Perguruan Tinggi Raharja.

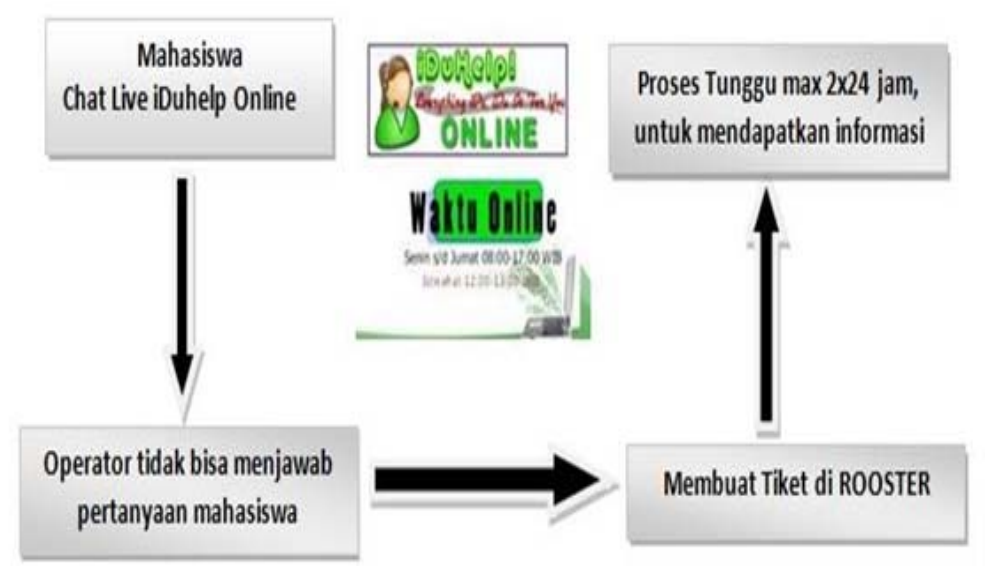

Gambar 4. Alur iDuHelp! Online

Melihat pada gambar diatas, maka proses kinerja ROOSTER sangat membantu untuk menjadikan pelayanan iDuHelp! menjadi lebih optimal dan proses kinerja ROOSTER yaitu dengan membuat tiket dan ditujukan kepada pihak terkait yang mampu menangani isi pesan dari operator iDuHelp!, kemudian kurang lebih dari 2x24 jam operator iDuHelp! akan mendapatkan sebuah jawaban dari Staff 
ROOSTER yang terkirimkan melalui email dan email tersebut akan dikirimkan kepada mahasiswa yang membutuhkan informasi tesebut. Dengan adanya kerjasama yang diciptakan oleh kedua sistem pelayanan ini, maka suatu pelayanan dapat memberikan kepuasan kepada mahasiswa dalam memberikan informasi.

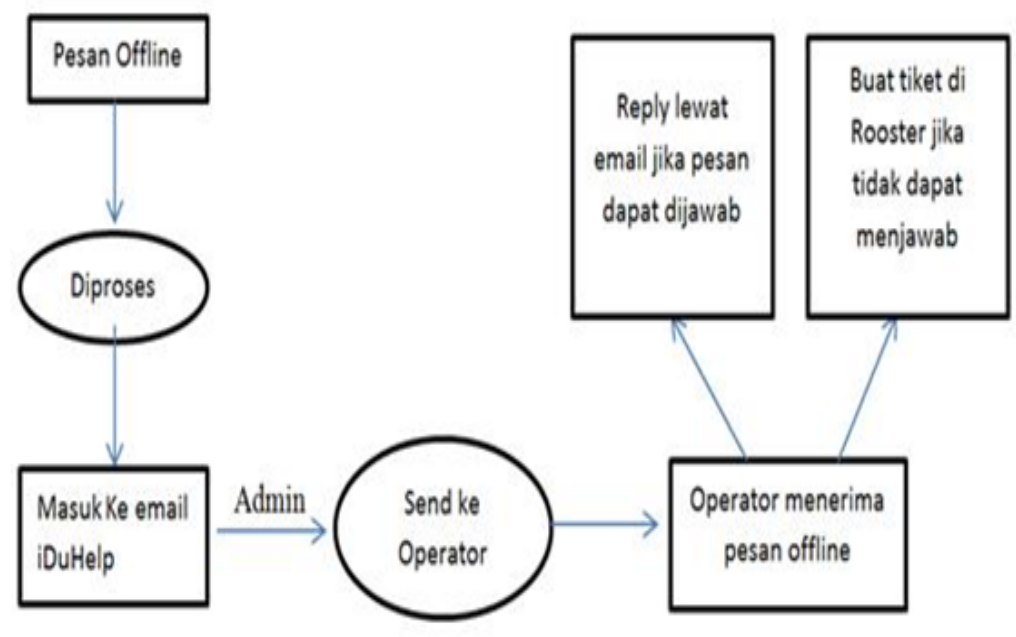

Gambar 5. Alur iDuHelp! Offline

Melihat pada alur iDuHelp! offline yang diterapkan Perguruan Tinggi Raharja, dijelaskan bahwa peranan ROOSTER saat ini hanya digunakan ketika suatu pertanyaan yang diterima kemudian pertanyaan tersebut tidak diketahui oleh operator iDuHelp!, sehingga dibutuhkan pelemparan jawaban dalam sebuah pembuatan tiket yang langsung dapat ditujukan kepada pihak yang terkait.

Hal ini menunjukan bahwa kinerja ROOSTER sebagai penunjang dari sistem iDuHelp! dapat memberikan kemudahan kepada operator iDuHelp! dan menjadi pilihan yang tepat jika pertanyaan tidak bisa dijawab oleh operator iDuHelp!.

Berdasarkan uraian yang telah dijelaskan diatas, maka diperlukan kecepatan dalam memperoleh informasi secara langsung dan jika operator tidak mengetahui informasi yang ada, maka membuat tiket yang ditujukan kepada pihak terkait sehingga kinerja ROOSTER sebagai media penunjang iDuHelp! berjalan dengan maksimal. Dalam hal ini bentuk pelayanan ROOSTER tidak terbatas, sehingga operator iDuHelp! dapat membuat tiket kapanpun dan dimanapun.

Dibawah ini merupakan gambaran flowchart alur program pengembangan dari sistem ROOSTER dalam menunjang sistem pelayanan iDuHelp!. 


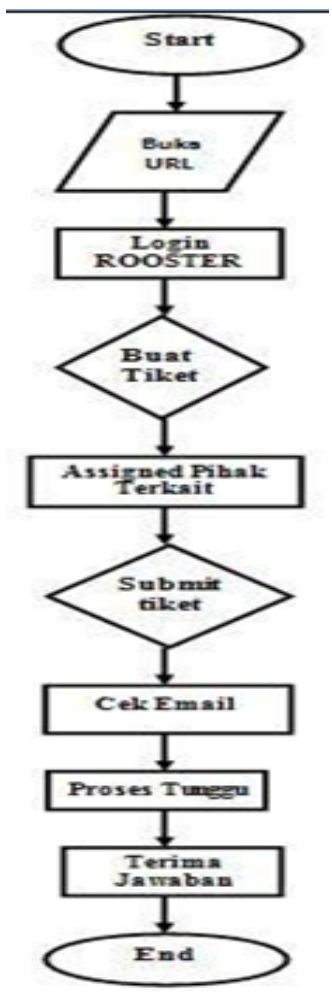

Gambar 6. Flowchart Sistem Pembuatan tiket ROOSTER.

Gambar diatas merupakan alur flowchart dalam sistem pembuatan tiket ROOSTER yang dituangkan untuk membantu pelayanan iDuHelp!, sehingga kinerja ROOSTER dalam menunjang pelayanan iDuHelp! sangat berkaitan erat, untuk mewujudkan pelayanan yang efesien dan efektif. Dengan adanya ROOSTER dapat memudahkan operator mendapatkan informasi apapun, dikarenakan dapat berinteraksi dengan pihak yang terkait, sehingga tidak lagi memakan waktu yang lama untuk mencari pihak yang terkait dalam mendapatkan sebuah informasi yang akurat.

Metode pengembangan meliputi 2 (dua) bagian pokok, yaitu Metode Analisis, yang dilakukan melalui tiga tahapan yaitu: identifikasi kebutuhan informasi, identifikasi persyaratan sistem, dan survey atas sistem yang sedang berjalan. Selain itu perancangan yang digunakan melalui UML (Unified Modeling Language) yang 
dibuat dengan menggunakan software Visual Paradigm, serta membangun sistem dengan menggunakan Macromedia Dreamweaver cs5[8].

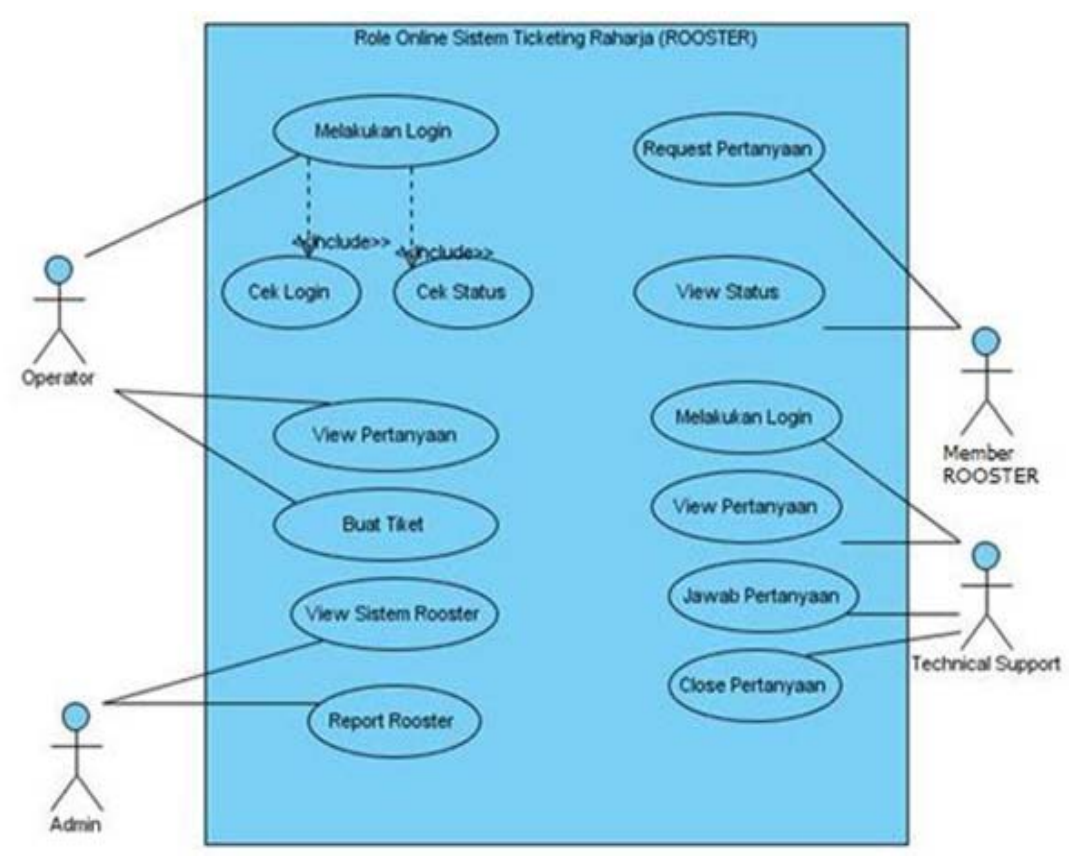

Gambar 7. Use Case Kinerja ROOSTER

Adapun 3 (tiga) ciri khas dari sistem kinerja ROOSTER yang merupakan konsep sistem pelayanan berbasis web, sehingga ciri khas yang pertama dari sistem kinerja ROOSTER yaitu dapat digunakan sebagai media pelayanan dukungan yang valid.

Yang kedua yaitu dapat berinteraksi secara online dengan pihak yang terkait sehingga dapat memudahkan dalam memperoleh informasi yang cepat dan akurat. Serta yang ketiga yaitu dapat mengantisipasi dan mencegah kemungkinan terjadinya kesalahan di dalam sistem pelayanan ROOSTER.

Dalam pengaksesan sistem pelayanan ROOSTER sebagai penunjang sistem pelayanan iDuHelp! ini, semua user sebagai pengguna sistem ini merupakan salah satu pendukung pelayanan ROOSTER, sehingga listing program yang akan ditampilkan yaitu listing program untuk program pembuatan tiket. Berikut adalah penggalan listing programnya: 


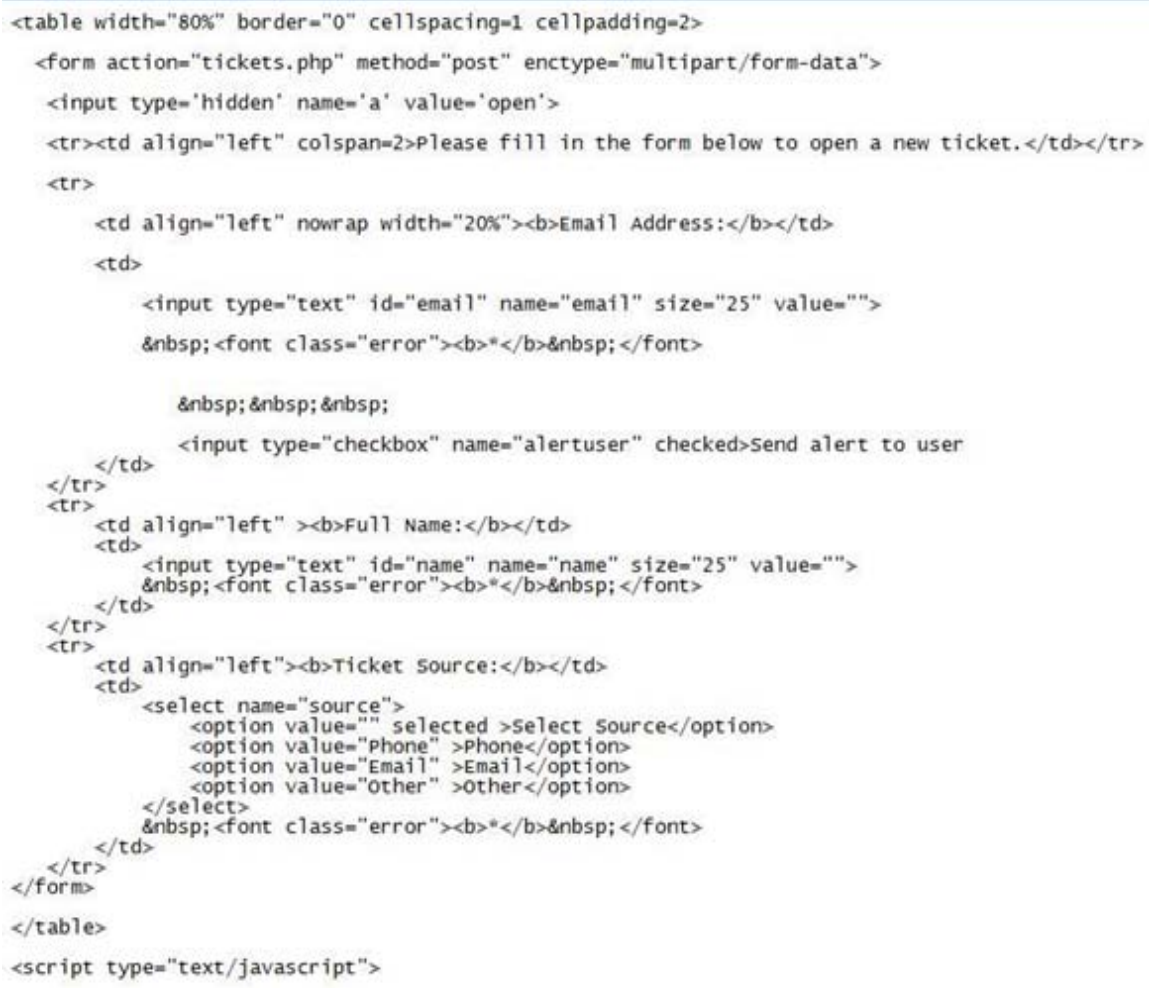

\section{Gambar 8. listing Program Create Ticket}

Maka dapat disimpulkan 4 (empat) keunggulan dan pemecahan masalah yang ada pada sistem pelayanan iDuHelp!. Pemecahan masalah yang pertama, yaitu ruang lingkup iDuHelp! dibatasi untuk masalah perkuliahan akademik, sehingga operator dapat membackup informasi yang dibutuhkan oleh mahasiswa. Pemecahan masalah yang kedua, yaitu bekerja sama dengan ROOSTER sehingga jika membutuhkan informasi yang sangat urgent bisa langsung berhubungan dengan pihak yang terkait. Pemecahan masalah yang ketiga, yaitu mengadakan simulasi pelayanan iDuHelp! dengan peranan kinerja ROOSTER, hal ini akan berdampak baik sehingga operator iDuHelp! dapat menguasai teknik dari sistem pelayanan iDuHelp!. Pemecahan masalah yang keempat, yaitu menjabarkan prosedur dengan jelas bahwa pelayanan iDuHelp! hanya diberikan dalam bentuk sebuah link, dan link tersebut berisi kebutuhan informasi yang diinginkan, hal ini dilakukan agar informasi yang didapatkan akurat. 


\section{IMPLEMENTASI}

Tampilan kinerja ROOSTER dalam menunjang dalam sistem pelayanan iDuHelp! memiliki macam figure yang dapat digunakan oleh operator iDuHelp! ataupun pihak yang terkait, yang terdiri dari:

\section{Tampilan Menu Login Operator iDuHelp!}

Tampilan menu Login ini digunakan oleh operator iDuHelp! saat ingin melakukan live chat dengan mahasiswa dan siap untuk melakukan obrolan.

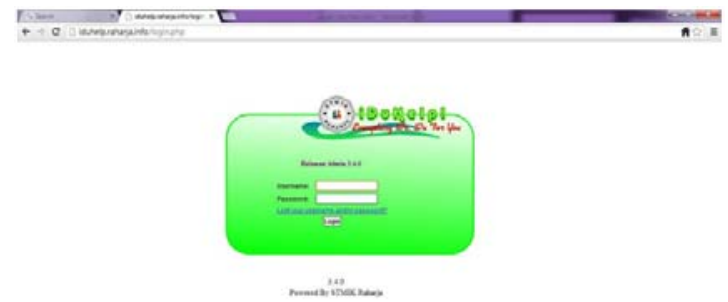

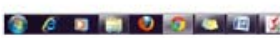

Gambar 9. Tampilan menu Login Operator iDuHelp!

2. Tampilan Live Chat Operator iDuHelp!

Tampilan Live Chat Operator iDuHelp! menandakan bahwa operator iDuHelp sedang dalam keadaan online dan menunggu mahasiswa online untuk mendapatkan informasi.

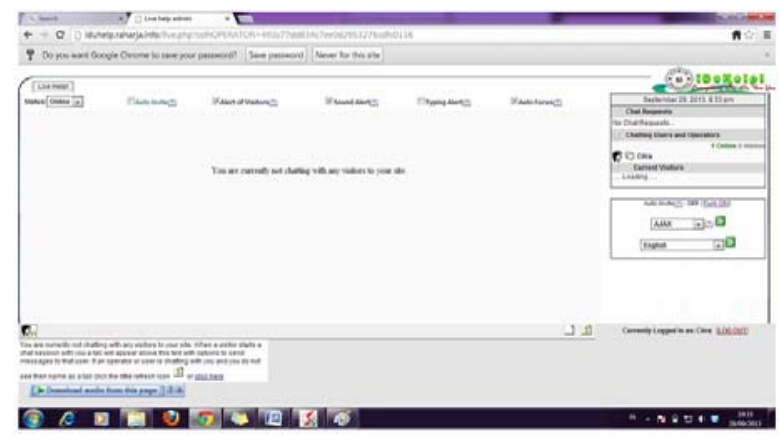

Gambar 10. Tampilan Live Chat Operator iDuHelp! 
3. Tampilan menu Login ROOSTER (Role Online System Ticketing Raharja)

Tampilan menu login ini digunakan oleh operator iDuHelp! untuk melakukan pembuatan tiket yang ditujukan kepada pihak terkait.

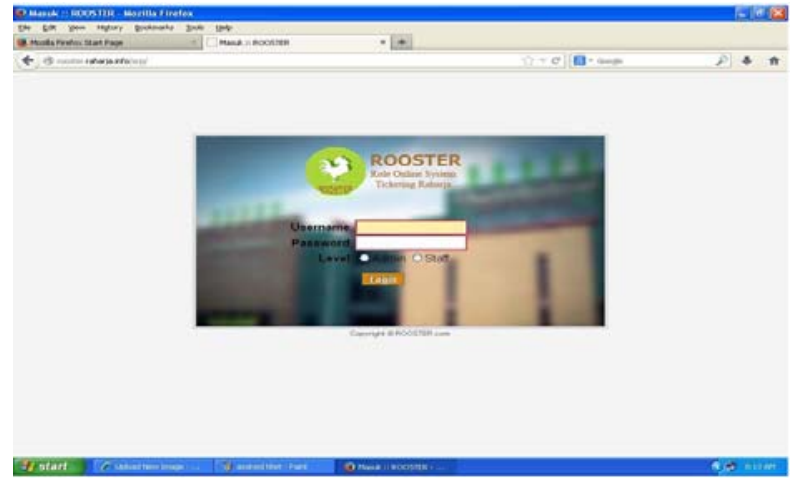

Gambar 11. Tampilan Menu Login ROOSTER

4. Tampilan formulir buat tiket ROOSTER (Role Online System Ticketing Raharja)

Dibawah ini merupakan formulir buat tiket yang akan dilakukan oleh operator iDuHelp!.

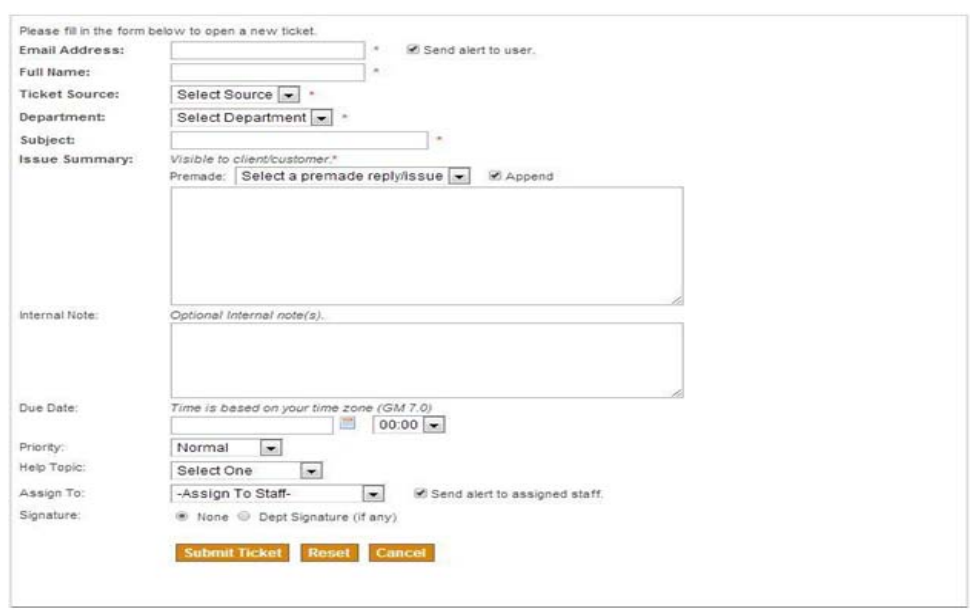

Gambar 12. Tampilan form Buat tiket ROOSTER 
5. Tampilan email jawaban ROOSTER (Role Online System Ticketing Raharja)

Dibawah ini tampilan email jawaban yang dikirimkan oleh pihak terkait untuk memberikan informasi yang dibutuhkan.

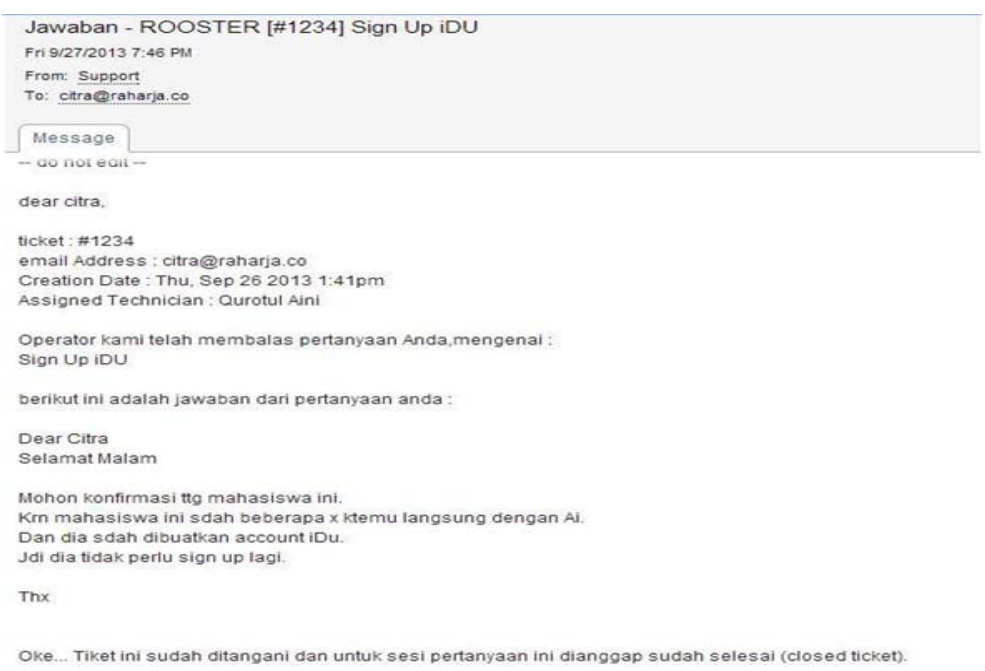

Gambar 13. Email Jawaban ROOSTER.

\section{KESIMPULAN}

Kinerja ROOSTER dalam menunjang sistem pelayanan iDuHelp! dapat bermanfaat khususnya bagi operator iDuHelp! dan kinerja ROOSTER bisa diakses kapanpun yang dibutuhkan, sehingga informasi yang didapatkan tepat dan akurat, hal ini juga dapat menjadi sarana penunjang yang bagus dalam menyampaikan informasi melalui sistem pelayanan iDuHelp!, sehingga dapat memberikan pelayanan yang optimal. Selain itu informasi yang didapatkan tidak lagi diragukan akan keakuratannya dan dapat disampaikan secara menyeluruh. Didalam sistem ROOSTER terdapat pula alternatif jalan yang memudahkan suatu pelaksanaan untuk melakukan proses tersebut, yaitu melalui view detail listing create ticket yang merupakan kinerja ROOSTER. Sehingga diharapkan dapat memudahkan operator iDuHelp! dalam memperoleh informasi yang tidak dapat diprediksi dan tentunya dengan adanya kinerja ROOSTER dapat menunjang sistem pelayanan iDuHelp! menjadi lebih optimal dalam proses pencapaian informasi. 


\section{DAFTAR PUSTAKA}

[1] iLearning, iDuHelp. http://iduhelp.ilearning.me/2013/01/11/hello-world/ (Diakses pada tanggal 11 Januari 2013). Widuri, iDuHelp. http:// widuri.raharja.infoindex.php?title=IDuHelp! . Halaman ini terakhir diubah pada 12.54, 08 Mei 2013. (diakses pada tanggal 15 April 2013). iRan, i D u H e l p. ht t p : / / i r a n. r a h a r ja.i n f o index.php?action=artikel\&cat=11\&id=10\&artlang=id (Diakses pada tanggal 18 Juni 2013).

[2] Hartati. Ery. "Sistem Pemesanan Dan Pembelian Tiket Bioskop Secara Online Dengan Menggunakan Active Server Pages.Net Berbasis Web Dan Wireless Application Protocol”. STMIK MDP Palembang, Indonesia 2008.

[3] Luo. Lili. "Chat Reference Competencies: Identification From a Literature Review And Librarian interviews”. University of North Carolina at Chapel Hill, Chapel Hill, North Carolina, USA, 2007.

[4] Olson. R. John. "Internet Ticketing InA Not-For-Profit, Service Organization: Building Customer Loyalty”. University of St Thomas, Minneapolis, Minnesota, USA, 2005.

[5] R. Untung, Sudarto. Ferry, Octavia. Linda .”iDuHelp!: Penerapan Campus Service System iDuHelp! Dalam Mendukung Kegiatan iLearning Education (IDU) Pada Perguruan Tinggi”. Perguruan Tinggi Raharja, Indonesia 2013.

[6] R. Untung, Azizah. Nur, Dewi. Santika .”Sistem Pelayanan Dukungan Role Online System Ticketing Raharja (ROOSTER) Dengan Menggunakan ETicket”. Perguruan Tinggi Raharja, Indonesia 2013.

[7] R. Untung, Yusup. Muhamad, Asmawati. Ari. "Digital Signature: Best Practise Solution For The Distribution On Geografis”. Perguruan Tinggi Raharja, Indonesia 2013.

[8] iRan,Rooster. http://iran.raharja.info index.php?action=artikel\&cat=26\&id=139\&artlang=id (Diakses pada tanggal 05 November 2013).

Info, Rooster. http://rooster.raharja.info/ (Diakses pada tanggal 06 November 2013). iLearning, Rooster. http://rooster.ilearning.me/2013/11/ 03/about-rooster/(Diakses pada tanggal 03 November 2013). Widuri, Rooster. http://widuri.raharja.info/index.php?title=Rooster . Halaman ini terakhir diubah pada 14.58, 15 Mei 2013. (diakses pada tanggal 06 November 2013) 